\title{
Experience of sexual intercourse in the first year after childbirth: women's views and attitudes
}

\author{
Anita Jug Došler, Ana Polona Mivšek, Petra Petročnik, Teja Škodič Zakšek, \\ Mateja Kusterle Jenko \\ University of Ljubljana, Faculty of Health Sciences, Midwifery Department, \\ Zdravstvena pot 5, 1000 Ljubljana, Slovenia \\ anita.jug@zf.uni-lj.si; polona.mivsek@zf.uni-lj.si; petra.petrocnik@zf.uni-lj.si; \\ teja.zaksek@zf.uni-lj.si; mateja.kusterle.jenko@gmail.com
}

\begin{abstract}
Introduction: Sexuality after childbirth depends on several factors that may affect a woman at the same time. The aim of the study was to research Slovenian women's experience of sexual intercourse in the first year after childbirth. Methods: A descriptive and causal nonexperimental method of empirical research has been used with a scientific literature review. A convenience sample of 3106 women was used and the data was gathered through an online questionnaire tool. The results were analysed with the use of SPSS ver. 20.0 statistical program. Results: Sixty-two percent of couples started with their sexual intercourse 6 to 8 weeks after childbirth. Sixty-two percent of participants reported their satisfaction with sexual intercourse was the same as in the period before childbirth. Thirty-six percent of women reported lower satisfaction with the sexual intercourse after birth. More than half of the women $(57 \%)$ had sexual intercourse less frequently after birth. Thirty-five percent of women reported they would like to have sexual intercourse more frequently. The most commonly reported problem after birth was dyspareunia. Discussion and conclusions: The results of the survey suggest some clear recommendations in terms of optimising the couples' sex life in the period after childbirth and in the first year of the child's life. Health care professionals have to be knowledgeable to share professional advice in the period after childbirth. Key words: pregnancy, sexuality, sexual intercourse, changes, partnership
\end{abstract}

exuality after childbirth depends on several factors that may affect a woman at the same time. In addition to the state of her reproductive organs and stimulation of her genitalia, it involves her desire and motivation for sexual intercourse, her general health and quality of life, the relationship with her partner, and emotional readiness to regain sexual intimacy with her partner. 
It also depends on successful attainment of the maternal role, on the ability to balance the maternal identity with the sexual identity and on the socio-cultural background, sexual habits of the couple before pregnancy and their emotional state (Barrett et al., 2000; Rezaee and Kinsberg, 2012; Trutnovsky, 2006)

Safe and satisfactory sex life is a basic human right (WHO, 2005). The childbearing period is a very vulnerable time in the sex life of a woman or a couple. Generally, sexual activity and intimacy significantly decrease during pregnancy, which can last up to several months after childbirth (Lee and Yen, 2007; Rezaee and Kinsberg, 2012; Boyd et al., 2013). Sexuality after childbirth includes much more than just a physical act of stimulating the genitalia. Hormonal changes during pregnancy affect the physical wellbeing and the mood of a pregnant woman and therefore the sex life of a couple (Trutnovsky et al., 2006). Avery et al. (2000) concluded that the desire for sexual intercourse between partners decreases after childbirth. Many couples begin with sexual intercourse in the first three weeks after childbirth, mostly on the male initiative, although doctors recommend sexual intercourse as late as after 6 weeks postpartum. Hormones related to breastfeeding may cause greater dryness of the vagina and consequently lower libido (Barrett et al., 2000). Dyspareunia and perineal pain account for common sensations accompanying women after childbirth and generally reduce the frequency of sexual intercourse between partners. Previous studies (Pacey, 2004; Barrett et al., 2000) write about a decrease in sexual activity during pregnancy; it being almost non-existent in the immediate postpartum period and then steadily increasing throughout the first year after childbirth when its frequency is approximately the same as in the time before pregnancy. In many respects, sexual function changes the most after childbirth (Pacey, 2004). Trutnovsky et al. (2006) in their research noted down the following factors that contribute to low sexual activity: sleep deprivation, stress, exhaustion, overload with the newborn care, dyspareunia and breastfeeding. During the postpartum period, sexual health problems in women are common. Many experience lower libido and decreased vaginal lubrication and frequently have shorter and weaker orgasms. Rathfisch et al. (2010) conducted a study that included healthy pregnant women with low level of risk that expected to have a vaginal delivery after 38 weeks gestation. Out of 165 women invited to a postnatal check-up 3 months after childbirth, 55 attended. There was a careful gynaecological examination and examination of the perineum, performed always by the same gynaecologist, followed by a 20-minute interview with each woman individually. The aim of the researchers was to compare sex lives of those women before and after childbirth. The findings revealed that women who experienced any perineal trauma, namely episiotomy or rupture, had lower libido, orgasm and sexual satisfaction and experienced more pain during sexual intercourse. Presence of at least one sexual problem (lower libido, decreased sexual arousal, decreased vaginal lubrication, reduced frequency of orgasm, dissatisfaction with sex life and dyspareunia) was statistically significantly more common after childbirth (Rathfisch et al., 2010). 
The aim and objective of the conducted research was to study Slovenian women's experience of sexual intercourse in the first year after childbirth. We posed 4 research questions, namely: (1) When did women initiate sexual intercourse after childbirth?, (2) are women equally satisfied with sexual intercourse before and after childbirth?, (3) how often do women have sexual intercourse after childbirth?, (4) do they and if they do, which problems do women most frequently encounter during sexual intercourse after childbirth?.

\section{Methods}

The research was based on the quantitative research paradigm, within which a descriptive and causal - nonexperimental method of empirical research was used. It was designed as an online questionnaire tool. Data was gathered through a questionnaire preliminarily tested on a pilot sample of ten respondents in order to verify comprehensibility of the questions asked. The survey was conducted from January 2013 to September 2015. Apart from demographical data, the questionnaire included basic questions in order to study Slovenian women's experience of sexual intercourse in the first year after childbirth.

To determine validity (\% of variance explained by the first factor) and reliability (\% of variance explained by common factors) of the measurement instrument, we used the results of factor analysis which showed that our research instrument is within acceptable limits of validity (first factor explained $\mathbf{2 3 . 2 \%}$ variance) and reliability (results of factor analysis revealed 3 factors that explain $60.9 \%$ variance).

A convenience sample of 3126 women who regionally cover all parts of Slovenia was used. Altogether, 3106 valid questionnaires were returned, which represents a responsiveness rate of $99.4 \%$. The largest group of women $(68 \%)$ was between 25 to 35 years old. The majority of women in the sample $(58 \%)$ achieved a university degree of education. The majority of women gave birth vaginally, namely $82 \%$, the remaining $18 \%$ delivered by a caesarean section.

The ethical aspects of the implementation of the research were provided based on A statement of voluntary participation and protection of personal data. Participation in the survey was voluntary and anonymous. The survey execution was approved by The Department of Midwifery, Faculty of Health Sciences in Ljubljana. Data processing was carried out at the level of descriptive statistics with calculations of frequencies, percentages and arithmetic mean. The data were processed using the statistical program SPSS 20.0. In order to determine statistically significant differences, we used Chi-square $\left(\chi^{2}\right)$ test. Where the conditions for $\chi^{2-}$ test were not fulfilled, Kullback test was implemented. The differences were confirmed as statistically significant at a value of $\mathrm{p}=0.05$. 


\section{Results}

In continuation, the results of the survey are presented in the same order as the preliminary research questions. With the first research question, we wanted to find out when the women started having sexual intercourse for the first time after childbirth (Table 1). We learnt that the majority of the women, $62.9 \%$, started having sexual intercourse 6 weeks to 2 months after the child was born. The mode of delivery (vaginal delivery, caesarean section) did not reveal any statistically significant differences $\left(\chi^{2}=21.028 ; \mathrm{g}=1 ; \mathrm{p}=0.577\right)$

Table 1: Initiation of sexual intercourse for women after childbirth.

\begin{tabular}{lc}
\multicolumn{1}{|c}{ When did you initiate sexual intercourse after childbirth? } & $f, f(\%)$ \\
\hline to 3 weeks after childbirth & $3(0.1)$ \\
\hline 3 to 6 weeks after childbirth & $313(10)$ \\
\hline 6 weeks to 2 months after childbirth & $1966(62.9)$ \\
\hline 2 to 6 months after childbirth & $656(21)$ \\
\hline 6 months to 1 year after childbirth & $188(6)$ \\
\hline after 1 year after childbirth or later & $/$ \\
\hline Total & $3126(100)$ \\
\hline
\end{tabular}

Note: $f$ : frequency; $f(\%)$ : percentage

With the second research question, we wished to learn if women are equally satisfied with sexual intercourse before and after childbirth (Table 2). $62 \%$ participants reported their satisfaction with sexual intercourse was the same as in the period before childbirth. There were $36 \%$ of the women who reported lower satisfaction and $2 \%$ of the participants who could not assess. None of the participants declared to be more satisfied with sexual intercourse after childbirth compared with sexual intercourse before childbirth. Also for this research question, the mode of delivery did not reveal statistically significant differences $\left(\chi^{2}=20.927 ; \mathrm{g}=1 ; \mathrm{p}=0.713\right)$.

\section{Table 2: Satisfaction of women with sexual intercourse after childbirth}

\section{How satisfied are you with sexual intercourse after childbirth? $\quad f, f(\%)$}

I am more satisfied with sexual intercourse after childbirth than I was before childbirth

I am equally satisfied with sexual intercourse after and before childbirth

I am less satisfied with sexual intercourse after childbirth than I was before childbirth

$1938(62)$

I cannot assess

$1125(36)$

Total

$63(2)$

3126 (100) 
In addition, we inquired about the frequency of sexual intercourse after childbirth (Table 3). More than a half of the women ( $57 \%$ ) have sexual intercourse less frequently after birth. Sexual intercourse is more frequent in $8 \%$ of the women. A great percentage of the women (35\%) could not give their assessment but would like to have sexual intercourse more frequently. The mode of delivery (vaginal delivery, caesarean section) did not reveal any statistically significant differences $\left(\chi^{2}=21.966 ; \mathrm{g}=1 ; \mathrm{p}=0.875\right)$.

Table 3: Frequency of sexual intercourse after childbirth

\section{How often do you have sexual intercourse after childbirth?}

After birth, I have more frequent sexual intercourse than before childbirth

After birth, I have less frequent sexual intercourse than before childbirth

I cannot assess but I would like to have more frequent sexual intercourse

I cannot assess but I would like to have less frequent sexual intercourse

Total

Note: $f$ : frequency; $f(\%)$ : percentage

As part of the last research question, we were interested whether women encounter any problems during sexual intercourse after childbirth; and if they do, which are the most frequent problems. Women report that the most common problem accompanying sexual intercourse after birth is dyspareunia (Table 4). It represents $32.2 \%$ of all answers. The mode of delivery did not reveal statistically significant differences $\left(\chi^{2}=21.103 ; \mathrm{g}=1 ; \mathrm{p}=0.943\right)$.

\section{Table 4: Problems women frequently encounter during sexual intercourse after childbirth}

\begin{tabular}{lc}
$\begin{array}{l}\text { Which of the problems/obstacles did you encounter most frequently during sexual } \\
\text { intercourse after childbirth? }\end{array}$ & $f, f(\%)$ \\
$\begin{array}{l}\text { I perceived changes in my vagina (strange bodily sensations, changed lubrica- } \\
\text { tion, etc.) }\end{array}$ & $156(5)$ \\
\hline $\begin{array}{l}\text { Dyspareunia (I feel pain during sexual intercourse) } \\
\text { Since childbirth, I have been constantly thinking of our baby even during sexu- } \\
\text { al intercourse }\end{array}$ & $534(17.1)$ \\
\hline Shortage of time & $616(19.7)$ \\
\hline $\begin{array}{l}\text { I had difficulties accepting my changed body after childbirth } \\
\text { Our relationship with my partner changed so much after childbirth that it influ- }\end{array}$ & $438(14)$ \\
\hline enced our sexual activity & $94(3)$ \\
\hline I did not have any problems/obstacles & $281(9)$ \\
\hline Other & $/$ \\
\hline Total & $3126(100)$ \\
\hline
\end{tabular}




\section{Discussion}

Changes in the period after childbirth can significantly affect the relationship between partners because sexuality plays an important role in their shared life. A childbirth may thoroughly change communication and sex life of a couple and therefore it is very important how partners accept their parent roles and at the same time remain sexual partners to each other. Based on the literature review and our survey we realised that about a third of the women (32.2\%) suffer from dyspareunia after childbirth, and the risk is even higher in the presence of former dyspareunia and labour interventions (Buhling et al., 2006; Klein et al., 2009). Woolhouse et al. (2014) discovered that psychological factors also influence the frequency of sexual intercourse and women's satisfaction with it. Caring for a child can cause stress to a woman. Like others, our research similarly confirmed that poor self-image of women after birth can cause lower libido. Namely, quite a percentage of the women (14\%) who answered our questionnaire had difficulties accepting their changed body after childbirth and some could not stop thinking of their baby during sexual intercourse (17\%).

A common challenge that couples face in the postpartum period is a lack of open discussion about sex between partners and a shortage of information available from health care professionals about the spectrum of factors that may influence couple's sexual function immediately or soon after childbirth. In our research, as much as $35 \%$ of the women want to experience sexual intercourse more often; nevertheless, it is encouraging that as much as $57 \%$ are satisfied with the frequency of sexual intercourse. Taking into consideration that as much as $36 \%$ of the women report being less satisfied with sex after childbirth, we can assume that the background reasons could be insufficient taking of sexual history and discomfort of women or couples to openly discuss sexuality and the troubles they encounter. Slovenian women rarely attend sex therapy due to the consequences of childbirth on their sex life (Škodič Zakšek, 2015). Moreover, sexologists are almost non-existent in Slovenia. If we assume this to be a standard part of midwifery treatment, midwives need additional knowledge and skills. Only in the past few years, the existing midwifery educational system has included emphasis on education about discussion and treatment of sexuality (Mivšek, 2015). Already during pregnancy women and their partners experience sexuality in different ways which may in turn affect the first sexual intercourse after childbirth and sex after childbirth in general (Makara-Studzińska et al, 2015). The latter can also affect the child and his or her sexual development (Jug Došler, 2015). In addition, Lee and Yen (2007) call attention to the fact that health care professionals should play a more active role and more openly discuss sexual activity and (lack of) sexual pleasure with both partners during the first postpartum check-up with the gynaecologist. They came to the conclusion that individualised approach is the most appropriate form of sex education in the postpartum period. We would like to point out that in Slovenia there is no adequate program for the screening of sexrelated problems that could improve the sex life of couples during very vulner- 
able periods such as pregnancy and postpartum. Gynaecological clinics present a great potential for the introduction of new changes but due to overload of work they often cannot offer sufficient psychosocial help, information and advice to couples about their sex life.

Based on the literature review and the survey results, we can summarize that the obtained findings bear great importance and that future research on the subject matter is vital because Slovenia lacks empirical research in this field. Research of sexuality opens a new window into the structure, functioning and relationship between partners after childbirth. Therefore, understanding of this process is crucial for tackling various problems or for an honest conversation between the couple and health care professionals.

\section{Conclusions}

The survey results represent a starting point for finding solutions in the field of improvement and satisfaction with sex life after childbirth, also in terms of receiving appropriate professional advice, information and assistance from health care professionals. Optimal sexual health is comprised of various physical and psychological factors and calls for an open dialogue that encourages women to discuss such sensitive issues openly. Female sexual dysfunction may be triggered by numerous factors of the endocrine system as well as many psychosomatic factors accompanied by anatomic changes during pregnancy and after childbirth, which in turn may also be influenced by mode of delivery. Almost $25 \%$ of the women after childbirth report experiencing sexual dysfunctions such as low libido, dyspareunia, anorgasmia and difficulty with lubrication. Most of them are related to lactation and/or are side effects of postpartum depression treatments. They also depend on the amount of rest and the amount of time and space for intimacy.

As appears evident from the survey, childbirth and challenges of the postpartum period influence the sex life of couples. In the postpartum period, women should receive enough information from health care professionals to live through it more easily. It is a responsibility of health care professionals to discuss it with women. Despite an abundance of literature on sexuality, it is limited to longitudinal methodological approaches and validation of standardized tools for situation assessments. Alongside, it would be essential to establish quality normative data on female and male sexual function in the postpartum period. We also need more research that would assess male sexual function and the role of the partner after childbirth.

\section{References}

AVERY, M.D., DUCKETT, L., FRANTZICH, C.R., 20oo. The experience of sexuality during breastfeeding Among primiparous women. Journal of midwifery and women's health, vol. 45, no. 3, pp. 228-237. 
BARRETT, G., PENDRY, E., PEACOCK, J., VICTOR, C., THAKAR, R., MANYONDA, I. 200o. Women's sexual health after childbirth. BJOG, vol. 107, no. 2, pp. 186-195.

BOYD, K., CHENEY, B., DAVIS, A., PLUMBO, M., SUNYECZ, J., THOMAS, M.A., 2013. Postpartum counseling: A quick reference guide for clinicians. Association of reproductive health professionals, [Datum dostopa 6. 5. 2017]. Dostopno na: http://www.arhp.org/uploadDocs/QRGpostpartum.pdf.

BUHLING, K. J., SCHMIDT, S., ROBINSON, J. N., KLAPP, C., SIEBERT, G., DUDENHAUSEN, J. W., 2006. Rate of dyspareunia after delivery in primiparae according to mode of delivery. European journal of obstetrics, gynecology, and reproductive biology, vol. 124, no. 1, pp. 42-46.

JUG DOŠLER, A. (2015). Raising children for a healthy sexual relationship in adulthood. In: Mivšek, A.P., ed. Sexology in midwifery. Rijeka: Intech.

KLEIN, K., WORDA, C., LEIPOLD, H., GRUBER, C., HUSSLEIN, P., WENZL, R., 2009. Does the Mode of Delivery Influence Sexual Function after Childbirth. Journal of Women's health, vol. 18, no. 8, pp. 1227-1231.

LEE, J.T. \& YEN, H.W., 2007. Randomized controlled evaluation of a theorybased postpartum sexual health education programme. Journal of Advanced Nursing, vol. 6o, no. 4, pp. 389-401.

MAKARA-STUDZIŃSKA, M., PLEWIK, I., KRYŚ, K..M., 2015. Sexual activity of women in different trimesters of pregnancy. European Journal of Medical Technologies, vol. 2, no. 7, pp. 1-9.

MIVŠEK, A.P., 2015. Do midwives need sexology in their undergraduate study? In: Mivšek, A.P., ed. Sexology in midwifery. Rijeka: Intech. [viewed 8 July 2017]. Available from: https://cdn.intechopen.com/pdfs-wm/47988.pdf

PACEY, S., 2004. Couples and the first baby: responding to new parents' sexual and relationship problems. Sexual and Relationship Therapy, vol. 19, no. 3, pp. 223-246.

TRUTNOVSKY, G., HAAS, J., LANG, U., PETRU, E., 2006. Women's perception of sexuality during pregnancy and after birth. Journal of obstetrics and gynaecology, vol. 46, no. 4, pp. 282-287.

RATHFISCH, G., DIKENCIK, B. ET AL. (2010). Effects of perineal trauma on postpartum sexual function. Journal of advanced nursing, vol. 66, no. 12, pp. 2640-2649.

REZAEE, R. \& KINSBERG, S., 2012. How to prepare your patient for the many nuances of postpartum sexuality. OBG Management, vol. 24, no. 1, pp. 24-38.

SERATI, M., SAlVATORE, S., SIESTO, G., CATTONI, E., ZANIRATO, M., KHULLAR, V., ET AL., 2010. Female Sexual Function during Pregnan- 
cy and after Childbirth. The Journal of Sexual Medicine, vol. 7, no. 8, pp. 278-290.

ŠKODIČ ZAKŠEK, T. 2015. Sexual Activity during Pregnancy in Childbirth and after Childbirth. In: Mivšek, A.P., ed. Sexology in midwifery. Rijeka: Intech. [viewed 8 July 2017]. Available from: https://cdn.intechopen.com/ pdfs-wm/48023.pdf 